\title{
Un poco de rock\&love. Recursos creativos empleados por las marcas en la publicidad para móviles
}

\section{A little rock\&love. Creative resources used by brands in mobile advertising}

\author{
José Martínez Sáez \\ Profesor Colaborador Doctor \\ (Universidad CEU Cardenal Herrera) \\ Marta Martín Núñez \\ Profesora Ayudante Doctora \\ (Universitat Jaume I de Castellón) \\ María Rosario García Cubells \\ Profesora Universidad \\ (Universidad CEU Cardenal Herrera)
}

Fecha de recepción: 21 de diciembre de 2014

Fecha de revisión: 8 de enero de 2015

Para citar este artículo: Martínez Sáez, J., Martín Núñez, M. y García

Cubells, M.R. (2015): Un poco de rock\&love. Recursos creativos empleados por las marcas en la publicidad para móviles, Icono 14, volumen (13), pp. 76-104. doi: 10.7195/ri14.v13i1.759 
77 | José Martínez Sáez, Marta Martín Núñez y María Rosario García Cubells

\section{Resumen}

Los cambios sociológicos, culturales y simbólicos que se han producido en la era digital han tenido una gran repercusión en el ámbito de la comunicación y evidencian que es necesario que las marcas tracen nuevos caminos en su búsqueda para conectar con sus públicos. Ante esta realidad, nuestra propuesta de rock\&love apuesta por un modo diferente de aproximarse a los públicos, más en sintonía con las nuevas posibilidades que brinda el contexto digital. Este artículo presenta una investigación en la que se parte de la hipótesis de que la comunicación para móviles —vehiculada a través de apps principalmente-es el terreno idóneo para que las marcas se comporten de acuerdo a los postulados del rock\&love y tiene como principal objetivo la identificación de los factores que permiten determinar cuáles son los recursos creativos que responden a los conceptos de rock y love. Para ello, se ha realizado un análisis de contenido a un corpus de trabajo compuesto por las campañas ganadoras del Festival Cannes Lions 2014 en la categoría de campañas móviles (mobile). Los resultados de la investigación, efectivamente, verifican los recursos creativos que responden al postulado del rock\&love en la comunicación publicitaria para móviles.

Palabras clave: Publicidad - digital - móvil - app - rock\&love - Festival Cannes Lions

\section{Abstract}

The sociological, cultural and symbolic transformations that have taken place in the digital age have had a major impact in media, and show that brands need to look for new paths to connect with their audiences. Within this context, our rock\&love proposition aims for a different way of approaching the public, in tune with the new possibilities offered by the digital context. This article presents a research in which we depart from the assumption that mobile media — apps, mainly — set the ideal ground for brands to behave according to the principles of rock\&love. Its main objetive is the identification of the creative resources that respond to the concepts of rock and love. We have carried out a content analysis of a body of work consisting of the winning campaigns of Cannes Lions Festival 2014 in the mobile category. Results verify the creative resources that respond to the postulates of rock\&love in mobile advertising campaigns.

Key Words: Advertising - digital - mobile - app - rock\&love - Cannes Lions Festival

ICONO14 | Año 2015 Volumen $13 N^{\circ} 1$ | ISSN: 1697-8293 | DOI: ri14.v13i1.759 


\section{Introducción}

Tradicionalmente se ha dibujado al sector publicitario como un sector muy atento a las dinámicas sociales y que se mantiene en la vanguardia de la creación de movimientos y tendencias sociales, pero quizá ésta sea una mirada edulcorada e idealista de la publicidad derivada del estereotipo del creativo avant la lettre, díscolo, rebelde y moderno. La publicidad es una institución más bien conservadora, como demuestra la forma en la que las agencias publicitarias consideradas mainstream se han adaptado a la era digital. El sector publicitario ha tardado mucho en adaptarse al nuevo ecosistema comunicativo generado a partir de Internet, si damos por hecho que se haya conseguido. Al principio se ignoró la publicidad en Internet en las grandes agencias dando así lugar al nacimiento de las llamadas agencias digitales. La propia denominación de digital ya actúa como síntoma de esa falta de adaptación al nuevo entorno que generaba Internet (McStay, 2010).

Esta investigación parte de los cambios sociológicos, culturales y simbólicos que se han producido en la era digital y que han tenido una gran repercusión en el ámbito de la comunicación. Evidencian que es necesario que las marcas tracen nuevos caminos en su búsqueda para conectar con sus públicos. Ante esta realidad, nuestra propuesta de rock\&love apuesta por un modo diferente de aproximarse a los públicos, más en sintonía con las nuevas posibilidades que brinda el contexto digital. Este artículo presenta una investigación en la que se parte de la hipótesis de que la comunicación para móviles — vehiculada a través de apps principalmente- es el terreno idóneo para que las marcas se comporten de acuerdo a los postulados del rock\&love y tiene como principal objetivo la identificación de los factores que permiten determinar cuáles son los recursos creativos que responden a los conceptos de rock y love. La mayoría de artículos científicos y técnico-profesionales publicados inciden en determinadas cualidades de los móviles para que éstos sean usados bajo la lógica del marketing tradicional como la ubicuidad, la capacidad de geolocalizar y la capacidad de personalizar. En el mejor de los casos hablan de la posibilidad de conversar gracias a la comunicación bidireccional que permiten (Smutkupt et al., 2010). Pero lejos de abundar en la lógica tradicional, a lo largo del artículo se explorarán las capacidades de los móviles como elemento para aportar valor a los consumidores bien vía la

DOI: ri14.v13i1.759| ISSN: 1697-8293 | Año 2015 Volumen 13 N 1 | ICONO14 
sorpresa (rock), bien vía el respeto por el consumidor (love). Pasamos a exponer el marco teórico en el que nos basamos y a continuación presentaremos la metodología de investigación como paso previo a la explicación de los resultados y la discusión de las conclusiones.

\subsection{Marco teórico}

Nuestra aproximación teórica al fenómeno de la publicidad digital se basa en las teorías que informan de las consecuencias sociológicas, culturales y simbólicas que se dan en el tránsito del «modelo difusión», cuyo medio de comunicación paradigmático era la televisión, al «modelo reticular» propio de la era digital (Martínez y Palao, 2009). Nos interesan los cambios que introduce lo digital más por lo que posibilita que por lo que es.

Castells (en Himanen, 2001: 113-115) define el informacionalismo de Himanen como «un paradigma tecnológico» que transforma la manera en la que consumimos productos culturales en Internet, cuyos tres rasgos esenciales son el aumento exponencial de la capacidad de procesamiento de la información, la capacidad de recombinar la información y la flexibilidad distributiva. Estos rasgos dan lugar a una suerte de «comunismo epistémico». Es la «nética» de Pekka Himanen que, por oposición a la ética protestante del capitalismo, apuesta por poner en común la información (2001: 11). Esto significa que los usuarios, gracias a Internet, pueden acceder libremente a los contenidos y gozar compartiendo libremente (sin coste) ese contenido. Este aspecto genera, como consecuencia, crisis en los modelos de negocio tradicionales llegando al aparentemente paradójico nacimiento de una economía de lo gratis (Anderson, 2009).

Castells habla del surgimiento una «sociedad-red» que posibilita una cultura de la autonomía (2012: 220). Su característica esencial es la ausencia de un centro de la información y su articulación en nodos. Si trasladamos esa idea a la publicidad podemos concluir que las marcas cada vez tienen menos control sobre su comunicación, que pasa a manos de los usuarios, articulados como nodos. De Kerckhove nos muestra otra perspectiva. A este ensayista lo que le ocupa y preocupa es la mutación que se da en el ser humano como consecuen-

ICONO14 | Año 2015 Volumen 13 N 1 | ISSN: 1697-8293 | DOI: ri14.v13i1.759 
cia de su adaptación e interacción con los medios digitales. En este sentido, la tesis de De Kerckhove es que el «hombre-masa», asociado al modelo difusión caracterizado por la televisión, se ha transformado en el «hombre-velocidad» propio del modelo reticular. Un «hombre-velocidad» que lo alcanza todo cuando quiere y desde donde quiere, puesto que el encuadre centrípeto (smartphone, tablet, portátiles) lo lleva adherido a su físico. «[...] [E]l hombre-velocidad de los ordenadores se encuentra en todas partes, en el centro de las cosas» (De Kerckhove, 1999: 160).

No obstante, los dos conceptos clave que estructuran el nuevo paradigma son el hipertexto y la interactividad. El hipertexto hace que la accesibilidad generalizada y la independencia de la secuencialidad implica la disolución de la noción de autor a favor de una concepción múltiple de la autoría (Manovich, 2006: 82; Darley, 2002: 215-218). Lo mismo podemos decir de la interactividad que supone, en potencia, la suspensión del acto clásico de la lectura posibilitando la modificación del transcurso de los relatos con importantes consecuencias en la creación de contenidos culturales y publicitarios. La calculabilidad del receptor de la publicidad tradicional le otorgaba un lugar ineludible en el discurso pero, en contenidos hipertextuales, el sujeto puede obviar la función de sutura e ignorar la coherencia textual. El resultado es el énfasis en la experiencia más que en el sentido, y el recurso al espectáculo y a lo sensitivo en el entretenimiento (y la publicidad) digital.

Todas estas cuestiones afectan al sistema de los medios de masas, que entran en crisis y, con ellos, el paradigma publicitario clásico. El problema, como señala McStay, es que cuando los medios tradicionales más necesidad tienen de incluir publicidad porque el público no quiere pagar por sus contenidos, la publicidad menos los necesita (2010: 23) porque la apuesta que realizan ahora es por contenidos transmedia que fluyen a través de diferentes medios (Scolari, 2009 y 2013). Se trata, pues, de «contenidos líquidos» respondiendo a la noción sociológica de Bauman (2003) o, como apunta Jenkins, contenidos esparcibles — spreadable, en ingés- (Jenkins et al., 2013). 


\subsection{Un poco de rock\&love: una propuesta para identificar recur- sos creativos en la publicidad de la era digital}

En la era digital es necesario que las marcas tracen nuevos caminos en su búsqueda para conectar con sus públicos. Lo que nosotros proponemos con nuestro rock\&love es un modo diferente de aproximarse a los públicos, más en sintonía con las nuevas posibilidades que brinda el contexto digital. De hecho, la interactividad que ofrecen es el campo idóneo para lograr el tan deseado engagement de los públicos con las marcas (Sheehan \& Morrison, 2013). Nuestra propuesta, no obstante, no es completamente original, ya que los conceptos de rock y love los hemos tomado prestados de propuestas originales que hemos observado en las últimas aportaciones teóricas y en la propia profesión publicitaria.

\subsubsection{El rock como préstamo}

El concepto de rock lo hemos tomado prestado del creativo Rafa Soto, socio fundador de la agencia Herraiz Soto \& Co. La primera vez que escuchamos a Soto reclamar que las marcas debían adoptar una actitud rockera fue en el congreso Brand Trends que se celebró en Valencia en abril de 2010 y que ahora abre el texto de presentación de su website. Para Rafa Soto el rock es una actitud. Una actitud de romper esquemas y moldes. Una actitud de estar continuamente buscando el riesgo para destacar. Una actitud que lleva a sorprender y emocionar a las audiencias, que hace que éstas perciban la vida como más estimulante y emocionante. Y cree que es así como deben actuar las marcas. En primer lugar, sorprendiendo, para poder ganarse la atención de sus públicos. En la era del acceso ilimitado a la información y del ruido publicitario, ganarse la atención del público objetivo es la primera condición de una comunicación eficaz al servicio de las marcas. $Y$, en segundo lugar, estimulando al receptor, haciéndoles sentir que vale la pena relacionarse con las marcas porque tienen algo interesante que aportarles.

\subsubsection{El love como préstamo}

El concepto de love lo tomamos prestado de Kevin Roberts y su Lovemarks (2005). Pero nuestra idea del love aplicado a las marcas va un poco más allá de donde Roberts deja su analogía. Para Roberts las marcas que consiguen ganarse la fidelidad de sus consumidores son aquellas que establecen un vínculo emocional con sus

ICONO14 | Año 2015 Volumen $13 N^{\circ} 1$ | ISSN: 1697-8293 | DOI: ri14.v13i1.759 
consumidores, que excede mucho la función racional de sus productos. Nuestra propuesta va más allá que la de Roberts porque él centra su discurso en cómo conseguir el amor de los consumidores, saltando así del concepto de posicionamiento de Ries y Trout - las marcas se posicionan en las mentes de los consumidores- a una idea de posicionamiento que podríamos decir sentimental —las marcas se posicionan en el corazón de los consumidores-. Nuestra idea de love propone que para lograr ese amor de los consumidores la marca debe dar amor. Uno recibe amor cuando da amor. $\mathrm{Y}$, en ese sentido, la aproximación a su público debe ser amigable, no intrusiva y respetuosa. Es un cambio en la perspectiva, que pasa de poner el foco de la comunicación en la USP (Unique Selling Proposition) de Roser Reeves, a la BERP (Beautiful, Entertaining and Relevant Proposition) que nosotros proponemos. Esto se puede conseguir, generalmente, a través de dos vías: la del advertainment o branded content - contenidos relevantes para el usuario - o vía la funcionalidad -información interesante, apps útiles para los dispositivos móviles, widgets, etc-.

\subsubsection{Red Bull como paradigma del rock\&love advertising}

Algunas marcas, como la austriaca Red Bull, llevan años apostando por una comunicación diferente, que encaja perfectamente con nuestra definición de rock\&love. Ya en su comunicación publicitaria convencional de hace más de una década adoptaba un tono y una forma que sorprendía y enganchaba al mismo tiempo que trataba con respeto al público. Eran anuncios divertidos que rompían con la norma jugando con la ironía propia de las tiras cómicas, que vimos en la mítica campaña Red Bull te da alas. No en vano, los espots estaban hechos con una animación y un diseño muy sencillo pero eficaz en términos de comunicación. En la actualidad, la marca de bebidas energéticas dispone de un conglomerado mediático propio, el Red Bull Media House, que ofrece contenidos diversos (largometrajes, cortos, documentales, reality-shows, retransmisiones...) generalmente anclados en los deportes de riesgo y en los desafíos humanos. Así fue el Red Bull Stratos, un acontecimiento que en octubre de 2012 captó el interés de millones de personas que lo siguieron en línea durante horas $\mathrm{y}$, además, atrajo el interés de los medios informativos a nivel global, que retransmitieron en directo el momento crucial: el salto estratosférico de Felix Baumgartner. La campaña, que fue un éxito a nivel comunicativo, tiene rock y tiene love. Pero ¿cómo identificar y definir exactamente cuáles pueden ser los recursos creativos que lleven al rock\&love?

DOI: ri14.v13i1.759| ISSN: 1697-8293 | Año 2015 Volumen 13 Nº 1 | ICONO14 


\section{Material y métodos}

\subsection{Justificación del objeto de estudio}

Como hemos argumentado en el marco teórico de la investigación, partimos de la premisa de que las marcas cada vez tienen menos control sobre sus comunicaciones y que los usuarios-consumidores poseen cada vez mayor control sobre las marcas. En consecuencia, las marcas precisan cambiar sus estrategias comunicativas para aproximarse a sus usuarios y consumidores, tratando de evitar (o minimizar) medios y formatos intrusivos. Es a lo que hemos referido más arriba con la expresión de rock\&love. En un entorno donde las presas del paradigma del cazador - que no son otras que las audiencias cautivas propias del paradigma tradicional que son sistemáticamente interrumpidas por la publicidad - se han liberado y empoderado, el recurso de las marcas no puede ser otro que buscar formas creativas que sorprendan y sean atractivas (el rock) $\mathrm{y}$, al tiempo, se muestren respetuosas y honestas con los usuarios/consumidores (el love) (Martínez, Martín y Amiguet, 2014).

Por otra parte, la premisa de De Kerckhove (citada con anterioridad) que habla de la mutación del «hombre-masa» al «hombre-velocidad» se materializa con toda su potencia con la popularización de los móviles y, más en concreto, con su evolución hacia los smartphones $\mathrm{y}$, en menor medida, a las tablets. Ese dispositivo, convertido en adminículo, que tanto nos facilita la vida - y nos desespera cuando lo hemos dejado olvidado- es el que pone en valor la tesis de De Kerckhove. Nunca antes habíamos tenido tanto poder para acceder al conocimiento desde cualquier lugar y en cualquier momento. A esto se suma que el índice de penetración de los móviles en España es de un 108,7\%, lo que implica que hay más móviles que ciudadanos $^{1}$. Dentro de la categoría móviles se incluyen los smartphones, cuya penetración es de un $84 \%{ }^{2}$.

No es extraño, pues, que desde el marketing tradicional, que busca encontrar a las audiencias para cazarlas de manera intrusiva, se lleve décadas pronosticando aumentos anuales de inversión publicitaria en móviles de más de dos dígitos porcentuales. Sin embargo, estas predicciones nunca se cumplen y la inversión en marketing móvil es de sólo un 0,9\% del total de inversión publicitaria en España ${ }^{3}$.

ICONO14 | Año 2015 Volumen 13 NN $^{\circ}$ | ISSN: 1697-8293 | DOI: ri14.v13i1.759 
Desde nuestro punto de vista, esa diferencia entre la optimista predicción y la tozuda realidad en la inversión publicitaria viene motivada por la percepción de la publicidad en móviles por parte de los usuarios. El móvil (o smartphone) es considerado un instrumento personal $\mathrm{y}$, por tanto, las llamadas comerciales y los mensajes publicitarios son, en su gran mayoría, considerados como intrusivos $\mathrm{y}$, en consecuencia, rechazados por los consumidores. Al menos es lo que también indican estudios como los de Heinonen y Strandvik (2003: 137-152). Sin embargo, las altas prestaciones de estos dispositivos — conectividad, movilidad, ubicuidad, 0 geolocalización - se prestan para elaborar mensajes diferentes a los tradicionales, más en sintonía con las peculiaridades de la era digital en la que vivimos. Así, en la comunicación móvil, el concepto de rock\&love se torna imprescindible, al apostar por una aproximación menos intrusiva, basada en contenidos relevantes o funcionales para el usuario donde sea él mismo quien acceda voluntariamente y que, además, le sorprendan y le enganchen, generando una experiencia satisfactoria con la marca. En este sentido, las aplicaciones (apps) son el vehículo principal -aunque no el único- para articular los mensajes publicitarios.

El dualismo en el uso publicitario de los dispositivos móviles - por un lado su carácter intrusivo y, por otro, el potencial de las apps como vehículo para aplicar nuestra propuesta de rock\&love - hace relevante y pertinente centrar la presente investigación -la identificación de los factores que determinan si una campaña o acción publicitaria tiene rock y/o love- en este campo.

La hipótesis de la que partimos es que la comunicación para móviles —vehiculada a través de apps principalmente- es el terreno idóneo para que las marcas se comporten de acuerdo a los postulados del rock\&love.

Para poder confirmar la hipótesis, deberemos atender un objetivo importante para la investigación: la identificación o el establecimiento de los factores que permiten determinar qué campañas o acciones publicitarias tienen rock y también love. Esos factores serán las categorías de análisis que aplicaremos al corpus de investigación. El objetivo no es realizar un análisis cuantitativo de la presencia de rock\&love en la publicidad en móviles, sino que trabajaremos este campo para validar nuestras categorías o factores de rock y love. Es decir, el objetivo del presente

DOI: ri14.v13i1.759| ISSN: 1697-8293 | Año 2015 Volumen 13 Nº 1 | ICONO14 
trabajo es identificar los factores que pudieran objetivar la identificación de la variable rock y de la variable love y para ello emplearemos como campo de análisis la publicidad en móviles.

\subsection{Método de la investigación}

El método que hemos empleado en la presente investigación es el análisis de contenido, que utilizaremos para obtener resultados cualitativos, puesto que nuestro empeño es comprender un fenómeno. Creemos que el análisis de contenido es la técnica más idónea porque, como afirma Berelson es «una técnica de investigación para la descripción objetiva, sistemática y cuantitativa del contenido manifiesto de las comunicaciones, con el fin de interpretarlas» (en Krippendorff, 1990: 29). Es decir, según esta aproximación, el análisis de contenido - aún siendo una técnica cuantitativa - tiene como fin la interpretación del fenómeno estudiado.

Para la selección del corpus de trabajo hemos recogido la lista de premiados de la categoría de mobile advertising del Festival Cannes Lions de 2014. A pesar de emplear una técnica que en primer término es cuantitativa, la vamos a utilizar de una forma cualitativa por dos motivos. Por una parte, el corpus lo componen 42 campañas, cifra claramente insuficiente para extraer conclusiones de corte cuantitativo; $\mathrm{y}$, por otra parte, porque hemos seleccionando las piezas premiadas en un festival publicitario - posiblemente el más exigente y la referencia del sector publicitario a nivel global-. Esto implica que, si una campaña ha sido premiada por su creatividad, tiene muchas posibilidades de contener factores de rock. Y, en la categoría de móviles, además, las campañas premiadas tendrán muchas probabilidades de contener factores de love, ya que difícilmente se premiarían campañas basadas en las estrategias tradicionales de intrusión y repetición. Por ello, si nos planteáramos objetivos de tipo cuantitativo estaríamos claramente sesgando el resultado. Sin embargo, nuestro objetivo es de identificación y validación de los factores de rock\&love, por lo que nos parece que la selección de este corpus puede revelarse como altamente clarificadora y eficaz.

Para afrontar el análisis necesitamos el establecimiento de los factores de rock y de love como categorías. Esta es una operación metodológica de riesgo pues nece-

ICONO14 | Año 2015 Volumen $13 N^{\circ} 1$ | ISSN: 1697-8293 | DOI: ri14.v13i1.759 
sariamente lo realizamos de forma heurística, basándonos en la cultura publicitaria atesorada gracias a la exploración libre de piezas publicitarias. Precisamente, el objetivo de la investigación se centra en la validación de los factores de rock y love propuestos aquí a priori.

De esta forma, planteamos un análisis de contenido ad hoc basado en la identificación de las siguientes categorías o factores:

1. Love: el establecimiento de esta cualidad es necesariamente bidireccional, como en cualquier relación afectiva. 0 bien la marca muestra amor a sus consumidores o bien los consumidores muestran amor hacia la marca, o bien se dan ambos casos y el amor se da en ambas direcciones a la vez.

- Cuando es la marca la que da amor a los consumidores es a través de funcionalidad. La pieza que ofrece la marca facilita la vida a sus usuarios.

- Cuando el amor es de los consumidores hacia la marca, o es bidireccional, generalmente es a través de contenidos que empoderan al usuario y lo hacen sentir bien. Las subcategorías que proponemos en las que este proceso puede tener lugar son las siguientes:

- Campaña que aporta un plus estético a través de una experiencia bella.

- Campaña que hace sentir más inteligente al usuario porque le aporta conocimiento.

- Campaña que premia al usuario vía la gamificación.

2. Rock: establecer los factores de rock implica enfrentamos a mayores dudas e inseguridades. Entendemos por rock la ruptura de las expectativas del usuario, la ruptura con las experiencias previas, con las reglas, con lo establecido y lo convencional. Pero ¿cómo establecer unos factores que identifiquen que una pieza tiene rock per se sin necesidad de una contextualización? Se trata de una operación complicada y de mayor riesgo. No 
obstante, la necesidad de buscar la objetivación nos anima a dar el paso aún a pesar de arriesgarnos y concluir la investigación con un fracaso. De esta forma, y con las reservas mencionadas, proponemos las categorías de análisis que pueden permitir establecer si las piezas tienen rock o no lo tienen:

- Campaña con humor, tan extraordinariamente divertida que potencialmente será compartida por el usuario.

- Campaña con tecnología innovadora, que sorprende al usuario porque la tecnología consigue un efecto nunca antes visto.

- Campaña que produce una experiencia intensa, que sorprende por su capacidad para generar empatía emocional con el mensaje.

- Campaña que consigue interacción con el usuario, le implica y éste participa en la difusión del mensaje.

- Campaña que demuestra generosidad de la marca. La comunicación publicitaria se presupone interesada, pero en ocasiones vemos acciones de las marcas que demuestran compromiso real y honesto con la sociedad. No nos referimos aquí a las acciones comúnmente amparadas bajo la etiqueta de la Responsabilidad Social Corporativa (RSC), sino a acciones en beneficio de la sociedad, a través de las cuales, evidentemente, la marca también se beneficia, como la acción de la campaña The fun theory de Volkswagen en Suecia.

Así, el método para la investigación ha consistido en identificar y listar las campañas ganadoras de la categoría Mobile del Festival Cannes Liones, analizar el contenido de los case study de las campañas y determinar si las piezas presentadas en las campañas contenían elementos de los previamente identificados como generadores de rock y love. 


\section{Resultados}

El análisis de contenido realizado a todos los estudios de caso del corpus compuesto por campañas ganadoras de la categoría móvil del Festival Cannes Lions ha permitido verificar y ajustar los factores de rock\&love que se proponían a priori en la investigación. La siguiente tabla resume los principales resultados del trabajo de campo, donde se describe brevemente y se justifican los factores de rock y de love que hemos identificado en cada campaña:

\begin{tabular}{|c|c|c|}
\hline $\begin{array}{c}\text { Campañas - Anunciante } \\
\text { (descripción) }\end{array}$ & LOVE & ROCK \\
\hline $\begin{array}{l}\text { A trip out to the sea - Guy } \\
\text { Cotten }\end{array}$ & $\begin{array}{l}\text { - Gamification: premia al usua- } \\
\text { rio si no muere, aunque es } \\
\text { imposible }\end{array}$ & $\begin{array}{l}\text { - Experiencia de cansacio que lleva } \\
\text { al ahogamiento } \\
\text { - Interacción con el usuario }\end{array}$ \\
\hline $\begin{array}{l}\text { Alvio } \\
\text { (juego para niños con } \\
\text { asma) }\end{array}$ & $\begin{array}{l}\text { - Funcionalidad (registro del } \\
\text { asma para los padres) } \\
\text { - Lúdico (juego para los niños) }\end{array}$ & $\begin{array}{l}\text { - Uso de la tecnología: un sopla- } \\
\text { dor integrado en el dispositivo } \\
\text { y un juego para monitorizar la } \\
\text { enfermedad } \\
\text { - Interacción con el usuario }\end{array}$ \\
\hline $\begin{array}{l}\text { Android Kit Kat } \\
\text { (unión de dos marcas con } \\
\text { fines comerciales) }\end{array}$ & $\begin{array}{l}\text { - Experiencia emotiva (un robot } \\
\text { android de chocolate) }\end{array}$ & $\begin{array}{l}\text { - Interacción: el usuario se implica } \\
\text { y participa en la difusión del } \\
\text { mensaje }\end{array}$ \\
\hline Babolat Play & $\begin{array}{l}\text { - Funcionalidad (registro de } \\
\text { información de raqueta) }\end{array}$ & $\begin{array}{l}\text { - Uso de la tecnología: monitoriza- } \\
\text { ción de la raqueta } \\
\text { - Interacción con el usuario }\end{array}$ \\
\hline $\begin{array}{l}\text { Beats music (streaming } \\
\text { para suministrar música } \\
\text { personalizada seleccionada } \\
\text { por especialistas) }\end{array}$ & $\begin{array}{l}\text { - Funcionalidad (música perso- } \\
\text { nalizada) }\end{array}$ & $\begin{array}{l}\text { - Uso de la tecnología: bases de } \\
\text { datos empleadas en el campo del } \\
\text { gusto musical }\end{array}$ \\
\hline $\begin{array}{l}\text { Bloody Tube } \\
\text { (sistema de televisión } \\
\text { interactiva) }\end{array}$ & $\begin{array}{l}\text { - Premia al usuario a través } \\
\text { de un sistema de puntos y } \\
\text { competición }\end{array}$ & $\begin{array}{l}\text { - Uso de la tecnología: televisión } \\
\text { interactiva }\end{array}$ \\
\hline
\end{tabular}

DOI: ril4.v13i1.759| ISSN: 1697-8293 | Año 2015 Volumen 13 Nº 1 | ICONO14 


\begin{tabular}{|c|c|c|}
\hline $\begin{array}{c}\text { Campañas - Anunciante } \\
\text { (descripción) }\end{array}$ & LOVE & ROCK \\
\hline $\begin{array}{l}\text { Bic Universal Typeface } \\
\text { (creación de una caligrafía } \\
\text { universal sumnado todas } \\
\text { las caligrafías individuales) }\end{array}$ & $\begin{array}{l}\text { - Experiencia estética deriva- } \\
\text { da del registro de la propia } \\
\text { caligrafía }\end{array}$ & - Interacción con el usuario \\
\hline $\begin{array}{l}\text { Catch-a-plane - Seven } \\
\text { planes (una app para } \\
\text { promocionar la aerolínea } \\
\text { repartiendo millas) }\end{array}$ & $\begin{array}{l}\text { - Premia al usuario dando millas } \\
\text { y descuentos para vuelos }\end{array}$ & $\begin{array}{l}\text { - Interacción y participación en la } \\
\text { difusión generada porque premia } \\
\text { con más millas si compartes el haber } \\
\text { ganado millas. }\end{array}$ \\
\hline $\begin{array}{l}\text { Donor Cable Project - Nar } \\
\text { Mobile (cable que permite } \\
\text { la donación de batería del } \\
\text { móvil que invita a donar } \\
\text { sangre) }\end{array}$ & $\begin{array}{l}\text { - Funcionalidad: cable que } \\
\text { transfiere batería de un móvil } \\
\text { a otro, con app que te indica } \\
\text { dónde se encuentran los do- } \\
\text { nantes y mensaje que recuerda } \\
\text { la donación de sangre } \\
\text { - Experiencia solidaria }\end{array}$ & $\begin{array}{l}\text { - Uso de la tecnología que permite } \\
\text { transferir batería de un móvil a } \\
\text { otro } \\
\text { - Generosidad de la marca con un } \\
\text { problema común (falta de donan- } \\
\text { tes de sangre) }\end{array}$ \\
\hline $\begin{array}{l}\text { Dumb ways to die - Mel- } \\
\text { bourne Metro } \\
\text { (videojuego que simula } \\
\text { diferentes formas de morir) }\end{array}$ & $\begin{array}{l}\text { - Lúdico: juego relacionado con } \\
\text { el mensaje de la campaña }\end{array}$ & $\begin{array}{l}\text { - Humor: tratamiento humorístico } \\
\text { y lúdico de la muerte } \\
\text { - Interacción con el usuario }\end{array}$ \\
\hline $\begin{array}{l}\text { Easyway lyrics (sincroniza } \\
\text { las letras de canciones con } \\
\text { las canciones y las traduce } \\
\text { a tiempo real) }\end{array}$ & $\begin{array}{l}\text { - Funcionalidad: permite obte- } \\
\text { ner las letras de las canciones } \\
\text { y sus traducciones a tiempo } \\
\text { real }\end{array}$ & $\begin{array}{l}\text { - Uso de la tecnología: bases de } \\
\text { datos aplicadas al campo musical }\end{array}$ \\
\hline $\begin{array}{l}\text { EL0 Teddy Bear } \\
\text { (Oso de peluche que alma- } \\
\text { cena mensajes de voz de } \\
\text { Whatsapp y los reproduce } \\
\text { al apretar la mano) }\end{array}$ & $\begin{array}{l}\text { - Funcionalidad: poner en } \\
\text { contacto a niños enfermos con } \\
\text { sus familias }\end{array}$ & $\begin{array}{l}\text { - Uso de la tecnología: whatsapp } \\
\text { en osos de peluche } \\
\text { - Experiencia intensa: combatir la } \\
\text { soledad de los niños enfermos }\end{array}$ \\
\hline $\begin{array}{l}\text { Food photos save lives } \\
\text { - UNICEF (campaña para } \\
\text { la donación de alimentos } \\
\text { al tercer mundo a través } \\
\text { de fotos de alimentos en } \\
\text { Instagram) }\end{array}$ & - Experiencia solidaria & $\begin{array}{l}\text { - Interacción: el usuario se implica } \\
\text { a través de los “me gusta" que } \\
\text { recibe de niños del tercer mundo } \\
\text { y participa en la difusión del } \\
\text { mensaje }\end{array}$ \\
\hline
\end{tabular}

ICONO14 | Año 2015 Volumen 13 Nº 1 | ISSN: 1697-8293 | DOI: ri14.v13i1.759 


\begin{tabular}{|c|c|c|}
\hline $\begin{array}{c}\text { Campañas - Anunciante } \\
\text { (descripción) }\end{array}$ & LOVE & ROCK \\
\hline $\begin{array}{l}\text { Friend Compass - Momon- } \\
\text { do (buscador de vuelos en } \\
\text { función de los destinos de } \\
\text { amigos) }\end{array}$ & $\begin{array}{l}\text { - Funcionalidad: sí, buscador de } \\
\text { vuelos }\end{array}$ & $\begin{array}{l}\text { - Tecnología: cruza datos de vuelos } \\
\text { con destinos de amigos en Face- } \\
\text { book } \\
\text { - Interacción con el usuario }\end{array}$ \\
\hline $\begin{array}{l}\text { Game of phones - Virgin } \\
\text { (juego de geolocalización) }\end{array}$ & $\begin{array}{l}\text { - Lúdico: juego de geolocaliza- } \\
\text { ción }\end{array}$ & $\begin{array}{l}\text { - Uso de la tecnología de geoloca- } \\
\text { lización para el juego con men- } \\
\text { sajes personalizados en pantallas } \\
\text { públicas } \\
\text { - Interacción con el usuario }\end{array}$ \\
\hline $\begin{array}{l}\text { Get well kit - Sanofi (fun- } \\
\text { da con pastillero integrado } \\
\text { y app de recordatorios) }\end{array}$ & $\begin{array}{l}\text { - Funcionalidad: pastillero y } a p p \\
\text { con recordatorios }\end{array}$ & $\begin{array}{l}\text { - Uso de la tecnología: calendario } \\
\text { y recordatorios para pastillas y } \\
\text { funda pastillero }\end{array}$ \\
\hline $\begin{array}{l}\text { Glasses.com } \\
\text { (Permite probarte dife- } \\
\text { rentes modelos de gafas a } \\
\text { través de una simulación) }\end{array}$ & $\begin{array}{l}\text { - Funcionalidad: permite probar- } \\
\text { te diferentes modelos de gafas } \\
\text { a través de una simulación }\end{array}$ & $\begin{array}{l}\text {-Tecnología: simulación de rostro } \\
\text { en 3D } \\
\text { - Interacción con el usuario }\end{array}$ \\
\hline $\begin{array}{l}\text { GT Ride. Viral Gaming for } \\
\text { KIA }\end{array}$ & $\begin{array}{l}\text { - Lúdico: juego relacionado con } \\
\text { el mensaje de la campaña }\end{array}$ & $\begin{array}{l}\text { - Uso de la tecnología: construc- } \\
\text { ción de la pista a través del } \\
\text { movimiento del móvil } \\
\text { - Interacción con el usuario a nivel } \\
\text { de cocreación de contenidos } \\
\text { (construcción de las pistas) }\end{array}$ \\
\hline $\begin{array}{l}\text { Guardian Angel (colgan- } \\
\text { te que con un toque se } \\
\text { conecta al móvil) }\end{array}$ & $\begin{array}{l}\text { - Funcionalidad: permite excu- } \\
\text { sarte o enviar geolocalización } \\
\text { en situaciones difíciles. }\end{array}$ & $\begin{array}{l}\text { - Uso de la tecnología: collar que } \\
\text { envía mensaje de autollamada o } \\
\text { socorro a un conocido con geolo- } \\
\text { calización }\end{array}$ \\
\hline $\begin{array}{l}\text { Kankhajura Station (radio } \\
\text { a través de móvil) }\end{array}$ & $\begin{array}{l}\text { - Funcionalidad: entretenimien- } \\
\text { to radiofónico a través de } \\
\text { móvil } \\
\text {-Conocimiento: proporciona } \\
\text { información, música, series, } \\
\text { chistes... }\end{array}$ & $\begin{array}{l}\text { - Uso de tecnología: utiliza el } \\
\text { móvil (llamadas de } 15 \text { minutos) } \\
\text { para hacer llegar contenidos y } \\
\text { publicidad a lugares donde no } \\
\text { llega la electricidad. }\end{array}$ \\
\hline
\end{tabular}




\begin{tabular}{|c|c|c|}
\hline $\begin{array}{c}\text { Campañas - Anunciante } \\
\text { (descripción) }\end{array}$ & LOVE & ROCK \\
\hline $\begin{array}{l}\text { Killing Kennedy - National } \\
\text { Geographic (webdoc sobre } \\
\text { el asesinato de Kennedy) }\end{array}$ & $\begin{array}{l}\text { - Aporta conocimiento y hace } \\
\text { sentir más inteligente al } \\
\text { usuario }\end{array}$ & $\begin{array}{l}\text { - Uso de la tecnología: uso del } \\
\text { multimedia interactivo para } \\
\text { representar la historia }\end{array}$ \\
\hline $\begin{array}{l}\text { Luna - Ing direct + UNICEF } \\
\text { (historia interactiva) }\end{array}$ & $\begin{array}{l}\text { - Experiencia bella / triste: } \\
\text { historia que da la vuelta en } \\
\text { función de la interacción del } \\
\text { usuario } \\
\text {-Experiencia solidaria }\end{array}$ & $\begin{array}{l}\text { - Interacción con el usuario: dando } \\
\text { la vuelta al móvil, da la vuelta a } \\
\text { la historia }\end{array}$ \\
\hline $\begin{array}{l}\text { Megafaces: Create your } \\
\text { own Olympic history - } \\
\text { Megafon (proyección de } \\
\text { selfies en pantanllas tridi- } \\
\text { mensionales en los JJ.00.) }\end{array}$ & $\begin{array}{l}\text { - Experiencia bella, al ver tu } \\
\text { rostro en una pantalla gigante } \\
\text { tridimensional }\end{array}$ & $\begin{array}{l}\text { - Uso de la tecnología: uso de leds } \\
\text { y sistema tridimensional }\end{array}$ \\
\hline $\begin{array}{l}\text { Movie Emoji - SingTel (pe- } \\
\text { lículas en el móvil gratis } \\
\text { si aciertas un acertijo de } \\
\text { emojis) }\end{array}$ & $\begin{array}{l}\text { - Funcionalidad: películas en el } \\
\text { móvil } \\
\text { - Premia al usuario con pelícu- } \\
\text { las gratis si resuelve acertijos } \\
\text { de emojis con el nombre de la } \\
\text { película. }\end{array}$ & $\begin{array}{l}\text { - Humor: nombres de películas en } \\
\text { emojis } \\
\text { - Interacción: los usuarios par- } \\
\text { ticipan con la cocreación de } \\
\text { acertijos }\end{array}$ \\
\hline $\begin{array}{l}\text { Movistar Connected with } \\
\text { Peru (sustituir el nombre } \\
\text { del operador por PERU } \\
\text { durante un día en los } \\
\text { dispositivos) }\end{array}$ & - Experiencia emotiva & $\begin{array}{l}\text { - Interacción: el usuario se implica } \\
\text { y participa en la difusión del } \\
\text { mensaje }\end{array}$ \\
\hline $\begin{array}{l}\text { Nike SB (app que registra } \\
\text { la actividad de los skaters) }\end{array}$ & $\begin{array}{l}\text { - Funcionalidad: registro de } \\
\text { actividad para skaters, con po- } \\
\text { sibilidad de grabar y archivar } \\
\text { vídeos de saltos } \\
\text { - Premia al usuario por objeti- } \\
\text { vos y progreso conseguidos }\end{array}$ & $\begin{array}{l}\text { - Tecnología: aplicación de la tec- } \\
\text { nología GPS y grabación de vídeo } \\
\text { para el registro del skate } \\
\text { - Interacción del usuario }\end{array}$ \\
\hline $\begin{array}{l}\text { Nivea kids - Nivea (pulsera } \\
\text { de geolocalización) }\end{array}$ & $\begin{array}{l}\text { - Funcionalidad: pulsera de geo- } \\
\text { localización para encontrar a } \\
\text { los niños en la playa con app }\end{array}$ & $\begin{array}{l}\text { Uso de tecnología: geolocalización } \\
\text { para encontrar a los niños } \\
\text { - Interacción del usuario }\end{array}$ \\
\hline
\end{tabular}

ICONO14 | Año 2015 Volumen $13 N^{\circ} 1$ | ISSN: 1697-8293 | DOI: ri14.v13i1.759 


\begin{tabular}{|c|c|c|}
\hline $\begin{array}{c}\text { Campañas - Anunciante } \\
\text { (descripción) }\end{array}$ & LOVE & ROCK \\
\hline $\begin{array}{l}\text { Not a stupid cover (funda } \\
\text { para móviles como si fuera } \\
\text { un libro) }\end{array}$ & $\begin{array}{l}\text { - Funcionalidad: funda de móvil } \\
\text { como si fuera un libro } \\
\text { - Experiencia bella y emotiva: } \\
\text { funda de libro para el móvil }\end{array}$ & \\
\hline $\begin{array}{l}\text { Offline Book - Math Paper } \\
\text { Press (fragmentos de libro } \\
\text { que aparecen cuando no } \\
\text { hay conexión a Internet) }\end{array}$ & $\begin{array}{l}\text { - Funcionalidad: proporciona } \\
\text { entretenimiento cuando no } \\
\text { hay cobertura de datos }\end{array}$ & $\begin{array}{l}\text { - Generosidad de la marca: ofrecen } \\
\text { parte del contenido gratis }\end{array}$ \\
\hline $\begin{array}{l}\text { Pay per laugh (app que } \\
\text { cuantifica las risas en el } \\
\text { teatro para pagar sólo por } \\
\text { lo que te ríes) }\end{array}$ & - Experiencia divertida & $\begin{array}{l}\text { - Humor: cuantifica las risas y } \\
\text { este hecho por sí mismo ya es } \\
\text { gracioso } \\
\text { - Tecnología: app que cuantifica } \\
\text { las risas }\end{array}$ \\
\hline $\begin{array}{l}\text { Penny the Pirate - OPSM } \\
\text { (libro y app infantil que } \\
\text { ayudan a detectar proble- } \\
\text { mas en la vista) }\end{array}$ & $\begin{array}{l}\text { - Funcionalidad: ayuda a detec- } \\
\text { tar problemas en la vista de } \\
\text { los niños }\end{array}$ & $\begin{array}{l}\text { - Uso de la tecnología: uso de } \\
\text { la lectura y la interacción para } \\
\text { detectar enfermedades } \\
\text { - Interacción del usuario }\end{array}$ \\
\hline $\begin{array}{l}\text { Racer, a Chrome expe- } \\
\text { riment - Google (juego } \\
\text { colaborativo basado en } \\
\text { navegador) }\end{array}$ & $\begin{array}{l}\text { - Lúdico: juego colaborativo } \\
\text { basado en navegador, en el } \\
\text { que varias pantallas se unen } \\
\text { para hacer una sola pista para } \\
\text { carreras }\end{array}$ & $\begin{array}{l}\text { - Tecnología: las pantallas se unen } \\
\text { para hacer un solo recorrido } \\
\text { - Interacción del usuario }\end{array}$ \\
\hline $\begin{array}{l}\text { S-Drive - Samsung (una } \\
\text { app que favorece la con- } \\
\text { ducción segura) }\end{array}$ & $\begin{array}{l}\text { - Funcionalidad: ofrece servi- } \\
\text { cios útiles para la conducción } \\
\text { (mapa, gps, tiempo, puntos } \\
\text { negros, tráfico) y bloquea / } \\
\text { activa funcionalidades durante } \\
\text { la conducción } \\
\text { - Premia al usuario con puntos } \\
\text { por cada milla segura, que } \\
\text { después se canjean en comer- } \\
\text { cios asociados e incluye un } \\
\text { modo colaborativo }\end{array}$ & $\begin{array}{l}\text { - Generosidad de la marca: com- } \\
\text { promiso con la reducción de los } \\
\text { accidentes de tráfico }\end{array}$ \\
\hline
\end{tabular}




\begin{tabular}{|c|c|c|}
\hline $\begin{array}{c}\text { Campañas - Anunciante } \\
\text { (descripción) }\end{array}$ & LOVE & ROCK \\
\hline $\begin{array}{l}\text { Search GPS - Rip Curl (re- } \\
\text { loj GPS y app que registra } \\
\text { la actividad de los surfe- } \\
\text { ros) }\end{array}$ & $\begin{array}{l}\text { - Funcionalidad: registro de } \\
\text { actividad para surferos (olas } \\
\text { surfeadas, velocidad, tiempo, } \\
\text { lugares, consejos) } \\
\text { - Premia al usuario comparan- } \\
\text { do sus estadísticas consigo } \\
\text { mismo u otros }\end{array}$ & $\begin{array}{l}\text { - Uso de la tecnología: aplicación } \\
\text { de la tecnología GPS a la práctica } \\
\text { del surf } \\
\text { - Interacción del usuario }\end{array}$ \\
\hline $\begin{array}{l}\text { Smart toys - Samsung } \\
\text { (jugar con juguetes físicos } \\
\text { da tiempo para jugar con } \\
\text { juegos en tablet) }\end{array}$ & $\begin{array}{l}\text { - Funcionalidad: juguetes físicos } \\
\text { que registran el uso y después } \\
\text { reinvierten el tiempo para } \\
\text { jugar en la tablet } \\
\text { - Premia al usuario } \\
\text { - Lúdico }\end{array}$ & $\begin{array}{l}\text { - Uso de la tecnología: cronómetro } \\
\text { que controla e iguala el tiempo } \\
\text { que los niños dedican al juego } \\
\text { físico que al juego interactivo }\end{array}$ \\
\hline $\begin{array}{l}\text { Strip comercial - Marisa } \\
\text { Commerce (potencia rega- } \\
\text { lar lencería comprando las } \\
\text { prendas que se quitan a la } \\
\text { modelo) }\end{array}$ & $\begin{array}{l}\text { - Funcionalidad: compra online } \\
\text { - Lúdica: juego de striptease }\end{array}$ & - Interacción del usuario \\
\hline $\begin{array}{l}\text { The minute of silence - } \\
\text { Anzac Appeal (un minuto } \\
\text { de silencio a través de } \\
\text { una llamada para hacer un } \\
\text { donativo a los veteranos } \\
\text { de guerra) }\end{array}$ & $\begin{array}{l}\text { - Experiencia solidaria y emo- } \\
\text { tiva }\end{array}$ & $\begin{array}{l}\text { - Experiencia intensa provocada } \\
\text { por el minuto de silencio } \\
\text { - Interacción: el usuario se implica } \\
\text { y participa en la difusión del } \\
\text { mensaje }\end{array}$ \\
\hline $\begin{array}{l}\text { The rolex daytona experi- } \\
\text { ment (permite experimen- } \\
\text { tar las prestaciones para } \\
\text { decidir la compra) }\end{array}$ & $\begin{array}{l}\text { - Funcionalidad: permite experi- } \\
\text { mentar las prestaciones }\end{array}$ & $\begin{array}{l}\text {-Uso de la tecnología: simulación } \\
\text { - Interacción con el usuario }\end{array}$ \\
\hline $\begin{array}{l}\text { Unlock lessons - Vivo } \\
\text { Telefonica (una app en la } \\
\text { que es necesario acertar } \\
\text { preguntas para desblo- } \\
\text { quear el móvil) }\end{array}$ & $\begin{array}{l}\text { - Funcionalidad: bloquea el } \\
\text { móvil hasta que los niños } \\
\text { aciertan una pregunta relacio- } \\
\text { nada con sus estudios. Envía } \\
\text { registro de progreso a los } \\
\text { padres } \\
\text { - Premia a los niños que acier- } \\
\text { tan preguntas }\end{array}$ & $\begin{array}{l}\text { - Interacción del usuario para } \\
\text { desbloquear el móvil }\end{array}$ \\
\hline
\end{tabular}




\begin{tabular}{|c|c|c|}
\hline $\begin{array}{c}\text { Campañas - Anunciante } \\
\text { (descripción) }\end{array}$ & LOVE & ROCK \\
\hline $\begin{array}{l}\text { Video stamp - Auspost } \\
\text { (mensaje de vídeo que } \\
\text { acompaña paquetes posta- } \\
\text { les en el sello a través de } \\
\text { un código QR) }\end{array}$ & $\begin{array}{l}\text { - Funcionalidad: permite enviar } \\
\text { mensajes de vídeo en correo } \\
\text { postal }\end{array}$ & $\begin{array}{l}\text { - Uso de la tecnología: aplicación } \\
\text { de la tecnología del código QR y } \\
\text { el vídeo a los envíos postales. }\end{array}$ \\
\hline $\begin{array}{l}\text { Wake up and smell the } \\
\text { bacon - Oscar Mayer (app } \\
\text { despartador que funciona } \\
\text { con olor de bacon) }\end{array}$ & $\begin{array}{l}\text { - Funcionalidad: despertador } \\
\text { con olor de bacon }\end{array}$ & $\begin{array}{l}\text { - Uso de la tecnología: aplicación } \\
\text { de los perfumadores a la alarma } \\
\text { del móvil }\end{array}$ \\
\hline $\begin{array}{l}\text { Written in the stars - } \\
\text { AKQA (servicio de mensajes } \\
\text { que se deben leer locali- } \\
\text { zando la estrella Polar) }\end{array}$ & $\begin{array}{l}\text { - Funcionalidad: enviar mensa- } \\
\text { jes diferentes } \\
\text { - Premia al usuario que localiza } \\
\text { la estrella Polar revelando el } \\
\text { mensaje } \\
\text { - Experiencia bella y emotiva, } \\
\text { con banda sonora de Massive } \\
\text { Attack }\end{array}$ & $\begin{array}{l}\text { - Uso de la tecnología: aplicación } \\
\text { de la tecnología de geolocaliza- } \\
\text { ción y GPS } \\
\text { - Interacción: el usuario se implica } \\
\text { para revelar el mensaje }\end{array}$ \\
\hline
\end{tabular}

Tabla 1: Campañas premiadas en la categoría Mobile en Cannes Lions e identificación de los factores de rock y love. Elaboración propia.

Los resultados muestran que la mayor parte de las campañas hacen uso de los principios que hemos agrupado bajo los conceptos del rock\&love. De una forma u otra, todas las campañas tienen una aproximación amable hacia el usuario y, además consiguen sorprenderlo rompiendo las expectativas. No obstante, el análisis realizado nos ha llevado a ajustar y matizar los factores identificados en la metodología como recursos creativos de rock y love. A continuación, por tanto, explicaremos en detalle cada factor de rock y love y lo ejemplificaremos con la descripción detallada de una campaña paradigmática del corpus para dar cuenta de los resultados de la investigación.

En el caso del love, hemos comprobado que la mayoría de las campañas aportan una funcionalidad determinada y ajustada al público objetivo al que se dirigen, lo que les permite demostrar su amor a los usuarios, haciendoles la vida más fácil. Un ejemplo que nos ha llamado la atención, es el de la campaña Donor Cable Project de Nar Mobile, en la que para conseguir aumentar las donaciones de sangre, regalaban 
al usuario una pulsera que sirve para transferir batería de un móvil a otro al comprar un nuevo móvil, algo que puede resultar muy útil para el usuario. En la pulsera se podía leer el mensaje: Dona energía para salvar al móvil. Dona sangre para salvar vidas, directamente relacionado con el propósito de la campaña. La pulsera funciona con una app que ofrece información e incluye un mapa con los donantes de bateria que se encuentran cerca. La campaña consiguió su propósito ofeciendo una solución simple a un problema común de los usuarios.

La mayoría de campañas en las que no existe una funcionalidad clara en la aplicación se tratan de un juego. Por tanto, el valor lúdico del juego es en sí mismo el motivo por el que los usuarios se descargan la aplicación. Esto nos ha hecho replantear este factor, que no habíamos tenido en cuenta antes, y añadirlo a los motivos por los cuales los usuarios aman la marca ( $\mathrm{y}$, consecuentemente, hacen uso de su aplicación). Un ejemplo paradigmático es la camapaña GT Ride. Viral Gaming de KIA. La campaña está enfocada a establecer relaciones con el público objetivo (masculino, joven y tecnológico) que puede estar interesado en el primer coche deportivo de KIA. El juego consiste en construir pistas de carreras a través del movimiento del dispositivo móvil (loops, curvas, etc), que después se pueden compartir y así retar a amigos para que jueguen. El juego no aporta funcionalidad pero proporciona el placer de jugar como modo de establecer una vía de comunicación amable y voluntaria con el usuario.

La previsión de los demás factores por los cuales los usuarios demuestran que aman la marca y, por ello, se descargan las aplicaciones, ha resultado ser acertado, aunque se han matizado. Existen aplicaciones que apelan a la felicidad de los usuarios, pero no tienen por qué ser sólo a través de una experiencia estética, como se había pensado en un principio. Hemos visto como esta felicidad puede venir por experiencias emotivas, solidarias o divertidas también. Este factor podría ser ampliable, aunque siempre dirigido a experiencias que hagan sentir bien a los usuarios. Así, efectivamente, la campaña Written in the stars, permite que los usuarios puedan enviar mensajes que sólo podrán ser leídos sí los destinatarios orientan sus dispositivos a la estrella Polar. Una vez localizada, aparece el mensaje dibujado como una constelación estelar con una banda sonora exclusiva del grupo Massive Attack, lo que más allá de la funcionalidad como servicio de mensajería, el usuario lo utilizará porque le permitirá disfrutar de una manera diferente (y bella) de comunicar-

ICONO14 | Año 2015 Volumen $13 N^{\circ} 1$ | ISSN: 1697-8293 | DOI: ri14.v13i1.759 
se con los suyos. No obstante, otras campañas también apelan a la felicidad del usuario a través de la emotividad y solidaridad, como el caso The minute of silence de Anzac Appeal, donde se instaba al público a guardar un minuto de silencio a través de una llamada telefónica con el fin de hacer un donativo a los veteranos de guerra; o también la campaña Pay per laugh, una app que cuantifica las risas en el teatro para pagar sólo por lo que el usuario se ríe, que apela de entrada a una experiencia divertida.

Otro de los factores contemplados consiste en apps que aportan conocimiento $\mathrm{y}$, por tanto, hacen sentir más inteligente al usuario. Aunque no abundan, sí existen magníficos ejemplos como el webdoc de National Geographic Killing Kennedy, que recoge, a través de un multimedia interactivo, un episodio de la historia contemporánea americana. De nuevo, el hecho de aportar información relevente para el usuario facilitará que sea éste quien busque y navegue por la aplicación de forma voluntaria.

El útlimo factor previsto era aquél que, a través de dinámicas de gamificación, recompensan y premian al usuario, enganchándolo al uso de la aplicación. Un ejemplo digno de mencionar es el S-drive de Samsung, una app para favorecer la conducción segura. Además de ciertas funcionalidades como ofrecer mapa, GPS, información sobre el tiempo, los puntos negros o el tráfico, bloquear la pantalla táctil y activar un sistema de voz cada vez que el usuario va conduciendo, la app premia al conductor por cada milla segura que recorre, que después puede canjear en comercios asociados. Este sistema de recompensa (y no de penalización, como los que normalmente se utilizan en tráfico) ha demostrado ser efectivo en el mantenimiento de los usuarios activos, fomentando la reducción de accidentes y muertes en accidentes de tráfico entre el público objetivo.

Por otra parte, también hemos analizado los factores de rock propuestos, es decir, aquéllos relacionados con la ruptura de expectativas, reglas e ideas preconcebidas por los cuales el mensaje genera sorpresa. En este caso, el rock ha sido más difícil de determinar porque está basado en cuestiones contextuales. Aún así, hemos identificado y verificado todos los factores propuestos en las piezas analizadas.

El primer factor de rock es el humor. Efectivamente, lo hemos encontrado en juegos como Dumb ways to die, un juego que representa muy bien el mensaje que se quiere dar a

DOI: ri14.v13i1.759| ISSN: 1697-8293 | Año 2015 Volumen 13 Nº 1 | ICONO14 
los usuarios, relacionado con tomar precauciones en situaciones absurdas pero cotidianas que pueden llevar a la muerte. La sencillez del diseño y la simpatía que desprenden los personajes contribuye en gran medida a que la pieza resulte en un juego divertido.

El segundo factor que hemos tenido en cuenta ha sido el del uso de tecnología novedosa para conseguir un efecto de sorpresa en el espectador. No obstante, en la mayoría de ocasiones la sorpresa no viene del uso de una nueva tecnología sino que se produce cuando tecnología ya existente se aplica a ámbitos en los que no se había aplicado todavía. Por tanto, hemos subdidividido este factor teniendo en cuenta esta puntualización. Un ejemplo del uso de tecnología novedosa lo vemos en la campaña Megafaces de Megafon, donde a través de unos paneles LED tridimensionales se proyectaban los selfies de los usuarios en los Juegos Olímpicos de invierno en Rusia. En este caso, la tecnología de paneles donde cada luz LED tiene una profundidad determinada para simular el rostro, puede considerarse novedosa. Por otra parte, campañas como ELO Teddy Bear, un oso de peluche que almacena mensajes de voz de Whatsapp y los reproduce al apretarle la mano, destinado a poner en contacto a niños enfermos con sus familiares, no emplea una tecnología novedosa pero sí lo es su campo de aplicación: la inmediatez de los mensajes de Whatsapp a través de un oso de peluche.

El tercer factor considerado en el análisis ha sido el que produce una experiencia intensa y sorprende al espectador por su capacidad para generar empatía emocional con el mensaje. La campaña $A$ trip out to the sea consiste en un vídeo interactivo en el que el protagonista cae al agua sin chaleco salvavidas forzando al usuario a hacer movimientos con el dedo en la pantalla hasta su extenuación, para evitar que el protagonista deje de nadar y se ahogue. La app consigue conectar emocionalmente con el espectador y transmitirle la angustia del náufrago que lucha contra el cansancio en el mar para evitar ahogarse, y así concienciar sobre el uso del chaleco salvavidas en alta mar.

El cuarto factor considerado en el análisis ha sido la interacción con el usuario. Evidentemente, por las características del medio en el que hemos centrado el corpus, la interacción se encuentra presente en todas las piezas, pero no siempre como factor de rock. Esto nos ha obligado también a diferenciar tres niveles: la simple interacción con el mensaje, el compromiso y participación en la difusión del

ICONO14 | Año 2015 Volumen $13 N^{\circ} 1$ | ISSN: 1697-8293 | DOI: ri14.v13i1.759 
mensaje y la co-creación de contenidos que enriquecen el mensaje. Por ejemplo, en una app lúdica como Dumb ways to die, existe una interacción con el usuario por el mero hecho de que se produce una situación de juego. No obstante, cuando la aplicación requiere la participación activa del usuario difundiendo la aplicación, la relación interactiva va un paso más alla, como sucede con la campaña Food Photos Save Lives, en la que se anima a los usuarios a donar dinero para alimentar a niños del Tercer Mundo a través de compartir fotos de platos con raciones alimenticias en Instagram en lugar de las fotos de los platos de comida habituales. Un paso más allá en la interacción se da cuando se invita al usuario como co-creador de contenidos. Esto lo vemos, por ejemplo, en la campaña Movie Emoji, de SingTel, donde se premia al usuario con una película gratis en el móvil si acierta su título en un acertijo de emojis. Después, se invita a los usuarios a crear sus propios acertijos con emojis.

Por último, el quinto factor considerado ha sido la generosidad de la marca con la sociedad. En este caso, uno de los ejemplos paradigmáticos es la aplicación SDrive de Samsung, que ya hemos analizado antes, una aplicación que favorece la conducción segura, y demuestra que la marca está comprometida con un objetivo social que va más allá de sus objetivos puramente comerciales.

\section{Discusión}

Tras el análisis realizado, nos disponemos a perfilar las principales conclusiones de la investigación. Debemos recordar que nuestro trabajo parte del convencimiento de que en una sociedad con un sistema de comunicación altamente atomizado y con un consumo de contenidos de comunicación cada vez más independiente de la lógica de los programadores (en virtud de las características del modelo reticular que confieren mayor poder al ciudadano) las marcas solo pueden conectar con sus públicos-objetivo si diseñan sus campañas bajo los principios del rock\&love.

De esta forma, nuestra hipótesis de partida se ha confirmado ya que hemos encontrado rock y love en todas las campañas analizadas, por tanto, la comunicación para móviles - vehiculada a través de apps principalmente- es el terreno idóneo para que las marcas se comporten de acuerdo a los postulados del rock\&love. Enten-

DOI: ri14.v13i1.759| ISSN: 1697-8293 | Año 2015 Volumen 13 N 1 | ICONO14 
demos el rock como la actitud de arriesgar rompiendo moldes para destacar y ganar la atención de sus públicos añadiendo emoción a sus vidas; y el love como fórmula para lograr la preferencia o amor de los consumidores dándoles valor y relacionándose con ellos de forma honesta, no intrusiva y respetuosa.

No obstante, la propia selección del corpus (las campañas premiadas en el Festival Cannes Lions en 2014) ya apuntaba una alta probabilidad de encontrar rock. Si estamos ante un festival que es la referencia de la creatividad global y fijamos el corpus en las piezas o campañas premiadas hemos de suponer que éstas lo son por su capacidad de sorprender. Así pues entendemos que el corpus era idóneo para nuestros fines. Debemos añadir, pues, que la comunicación creativa para móviles es el terreno idóneo para que las marcas se comporten de acuerdo a los postulados del rock\&love, ya que entendemos que no toda la comunicación que se realiza para el móvil tiene la dosis necesaria de creatividad.

Por otra parte, nuestro objetivo en esta investigación era identificar los factores que permitieran objetivar la identificación del contenido rock y del contenido love en la publicidad en móviles. Tras el análisis del corpus encontramos que los factores establecidos previamente de forma heurística para objetivar la presencia de la variable rock y de la variable love se revelan bastante eficaces, aunque ha sido necesario ajustarlos y matizarlos. Así, se han establecido dos categorías para determinar la variable love en las campañas publicitarias y en una de esas categorías, la de empoderamiento del usuario, se han establecido cuatro subcategorías. La primera subcategoría, que hace referencia a felicidad del usuario haciéndolo sentir bien a través de una experiencia se ha concretado en cuatro casos: estética, emotiva, solidaria o divertida. La aportación lúdica al usuario mediante juegos se ha añadido como cuarta subcategoría, ya que no había sido tenida en cuenta al principio de la investigación.

Por lo que respecta a la variable rock, las cinco categorías o factores se han revelado como eficaces para determinar la capacidad de sorpresa que encierra una campaña publicitaria (en este caso en publicidad en móviles). Pero el análisis nos ha forzado también a señalar algunas subcategorías. Así esa operación de completar o matizar las categorías se ha dado en dos de los factores de la variable rock. Por una parte, cuando la campaña o acción consigue sorprender al usuario mediante la tecnología

ICONO14 | Año 2015 Volumen $13 N^{\circ} 1$ | ISSN: 1697-8293 | DOI: ri14.v13i1.759 
hemos observado que esta ruptura de expectativas $\mathrm{y}$, por consiguiente, esta llamada a la atención del usuario vía tecnología puede ser bien porque la tecnología es novedosa, bien porque aún no siendo novedosa su aplicación se da en contextos nuevos. El establecimiento de subcategorías también se ha dado en el factor de interacción del usuario. Hemos comprobado que como categoría era excesivamente genérica y que convenía establecer las subcategorías para matizar o precisar la forma o calidad de la interacción del usuario con la propuesta de la marca. Así, en este caso, hemos establecido tres subcategorías que van desde la mera interacción con el mensaje; la interacción que fomenta el compromiso con el mensaje de la marca y facilita la difusión por parte del usuario (viralización); y la interacción que facilita y estimula al usuario para participar de la co-creación del mensaje de la marca, enriqueciéndola.

Las siguientes tablas dan cuenta de las categorías y subcategorías para cada una de las variables de rock\&love:

\begin{tabular}{|l|l|}
\hline \multicolumn{2}{|c|}{ Variable Love } \\
\hline \multicolumn{1}{|c|}{ Categorías } & \\
\hline $\begin{array}{l}\text { La marca da amor a los consumidores es a través } \\
\text { de funcionalidad. La campaña que ofrece la marca } \\
\text { facilita la vida a sus usuarios. }\end{array}$ & \multicolumn{1}{|c|}{ Subcategorías } \\
\hline & $\begin{array}{l}\text { 1. Campaña que apela a la felicidad del usua- } \\
\text { rio haciéndolo sentir bien a través de una } \\
\text { experiencia estética, emotiva, solidaria } 0 \\
\text { divertida. } \\
\text { Campaña que aporta conocimiento y hace } \\
\text { sentir más inteligente al usuario. }\end{array}$ \\
$\begin{array}{l}\text { El usuario ama a la marca porque le ofrece conte- } \\
\text { nidos que lo empoderan como usuario y lo hacen } \\
\text { sentir bien. }\end{array}$ & $\begin{array}{l}\text { 3. Campaña que premia al usuario vía la ga- } \\
\text { mificación. } \\
\text { 4ampaña que aporta una experiencia lúdi- } \\
\text { ca a través del juego. }\end{array}$ \\
\hline
\end{tabular}

Tabla 2: Factores de love. Elaboración propia. 


\begin{tabular}{|c|c|}
\hline \multicolumn{2}{|c|}{ Variable Rock } \\
\hline Categorías & Subcategorías \\
\hline \multicolumn{2}{|l|}{$\begin{array}{l}\text { Campaña basada en el humor, tan extraordinaria- } \\
\text { mente divertida que potencialmente será compar- } \\
\text { tida por el usuario. }\end{array}$} \\
\hline $\begin{array}{l}\text { Campaña con tecnología novedosa. La sorpresa del } \\
\text { usuario se produce porque la tecnología } \\
\text { consigue un efecto nunca antes visto. }\end{array}$ & $\begin{array}{l}\text { 1. Novedad de la tecnología en sí. } \\
\text { 2. Aplicación distinta de una tecnología ya } \\
\text { existente. }\end{array}$ \\
\hline \multicolumn{2}{|l|}{$\begin{array}{l}\text { Campaña que produce una experiencia intensa, } \\
\text { que sorprende por su capacidad para generar em- } \\
\text { patía emocional con el mensaje }\end{array}$} \\
\hline $\begin{array}{l}\text { Campaña que consigue interacción } \\
\text { con el usuario. }\end{array}$ & $\begin{array}{l}\text { 1. Interacción con el mensaje } \\
\text { 2. Compromiso y participación en la difusión } \\
\text { del mensaje } \\
\text { 3. Co-creación de contenidos que enriquecen } \\
\text { el mensaje }\end{array}$ \\
\hline Campaña que demuestra generosidad de la marca. & \\
\hline
\end{tabular}

Tabla 3: Factores de rock. Elaboración propia.

Por último, quisiéramos reseñar las posibles vías de futuras investigaciones que emergen como consecuencia de los resultados del presente trabajo.

Al fijar el corpus en las campañas premiadas en un festival que valora la creatividad, la propia selección sesga el resultado puesto que la variable rock (el componente de sorpresa), es en sí mismo un valor creativo. Por eso, una primera posible línea de futuras investigaciones sería comprobar si las campañas que según nuestra metodología poseen las variables del rock\&love son campañas más eficaces desde el punto de vista de su contribución a la consecución de los objetivos de marketing de las marcas anunciantes. Para ello, el análisis no debería limitarse a una determinada técnica, como ha sido el marketing móvil en este caso, sino que debería contemplar campañas integradas, e idealmente el corpus de la investigación debería resultar de los Effies, los festivales que miden la eficacia publicitaria que se realizan en diferentes países, con versiones en el ámbito español, europeo y global. 
También sería interesante validar el análisis con una muestra más amplia y que, además, no basara el criterio de selección en la presencia de las campañas 0 acciones analizadas en festivales publicitarios. Podríamos así, una vez validadas las categorías de análisis como hemos realizado aquí, aplicar la metodología a una muestra que permitiera, ahora sí, unas conclusiones de corte cuantitativo.

Por último, nuestra inquietud también dirige su atención al campo de las aplicaciones móviles (las denominadas apps). Por su naturaleza, las aplicaciones móviles son territorio natural para que se dé la variable love de nuestra propuesta. Un análisis de aplicaciones móviles basado en la selección de una muestra compuesta por las aplicaciones más descaragadas creadas por marcas podría ayudar a establecer un modelo de creación de aplicaciones que responda a la lógica del rock\&love.

\section{Notas}

[1] Datos extraídos del Observatorio Nacional de las Telecomunicaciones y de la Sociedad de la Información (ONTSI) dependiente del Ministerio de Industria, Energía y Turismo y consultables en http://www.ontsi.red.es/ontsi/es/indicador/evolución-del-número-de-clientes-detelefon\%C3\%ADa-móvil-en-españa (consultado el 7 de octubre de 2014).

[2] Datos de un estudio de Ametic y Accenture publicados en ABC el 12 de septiembre de 2014. Acceso a edición digital http://www.abc.es/tecnologia/20140912/rc-penetracion-smartphones-espana-duplica-201409121339.html (Consultado el 7 de octubre de 2014).

[3] Datos de Infoadex, cuyos informes son la referencia para el control de la inversión publicitaria en España. Acceso en http://www.infoadex.es/nota_de_prensa_marzo14.pdf (consultado el 7 de octubre de 2014).

[4] Se puede consultar esta campaña en: http://www.thefuntheory.com

\section{Referencias}

Anderson, C. (2009). Gratis. El futuro de un precio radical. Barcelona: Ediciones Urano.

Bauman, Z.(2004). Modernidad líquida. México D.F.: Editorial Fondo de Cultura Económica.

Bolter, D.J. y Grusin, R. (2011). Inmediatez, hipermediación, remediación. CIC Cuadernos de información y comunicación. Vol. 16, pp. 29-57.

DOI: ri14.v13i1.759| ISSN: 1697-8293 | Año 2015 Volumen 13 Nº 1 | ICONO14 
103 | José Martínez Sáez, Marta Martín Núñez y María Rosario García Cubells

Castells, Manuel (2012). Redes de indignación y esperanza. Madrid: Alianza Editorial.

Darley, A. (2002). Cultura Visual Digital. Espectáculo y nuevos géneros en los medios de comunicación. Barcelona: Paidós.

Heinonen, K. y Strandvik, T. (2003). Consumer responsiveness to marketing communication in digital channels. M. Hannula, A-M. Järvelin \& M. Seppä (Ed.) Frontiers of e-Business Research 2002 (pp. 137-152). Tampere University of Technology and University of Tampere.

Himanen, P. (2001). La ética del hacker y el espíritu de la información. Barcelona: Destino.

Jenkins, H. (2008). Convergence culture. La cultura de la convergencia de los medios de comunicación. Barcelona: Paidós.

Jenkins, H. (2013). Spreadable Media. Creating value and meaning in a networked culture. New York: New York University Press.

Kerckhove, D.(1999). La piel de la cultura. Investigando la nueva realidad electrónica. Barcelona: Gedisa.

Krippendorf, K. (1990). Metodología de análisis de contenido. Teoría y práctica. Barcelona: Paidós.

Manovich, L.(2006). El lenguaje de los nuevos medios de comunicación. La imagen en la era digital. Barcelona: Paidós Comunicación.

Martínez Sáez, J. y Palao, J.A. (2009). El cine y el entorno visual. Material docente Módulo La innovación en la obra audiovisual. Valencia Internacional University. Recuperado de http://www.viu.es. Consultado el 27/09/10.

Martínez, J., Martín, M. y Amiguet, J.M. (2014). Rock\&love advertising in luxury fashion brands. CIMODE 2014, 2nd International Fashion and Design Congress Proceedings. Milano, pp. 551-559.

McStay, A. (2010). Digital Advertising. London: Palgrave Macmillan.

Roberts, K. (2005). Lovemarks. El futuro más allá de las marcas. Barcelona: Urano.

Scolari, C. (2009). Transmedia Storytelling: Implicit Consumers, Narrative Worlds, and Branding in Contemporary Media Production. International Journal of Communication, 3, pp. 586-606.

Scolari, C. (2013). Narrativas Transmedia. Cuando todos los medios cuentan. Barcelona: Deusto.

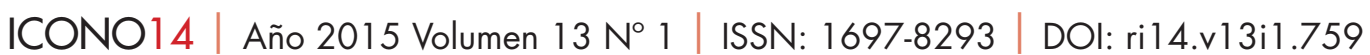


Sheehan, K. B. y Morrison, D. K. (2013). The Creativity Challenge. En Journal of Interactive Advertising, 9:2, pp. 40-43.

Smutkupt, P., Krairit, D. \& Esichaikul, V. (2010). Mobile Marketing: Implications for Marketing Strategies. International Journal of Mobile Marketing, vol.5, n², pp.126-139.

Solana, D. (2010). Postpublicidad. Barcelona: Double You. 